\title{
Analysis of drape co-efficient, bending length, flexural rigidity and tightness factor of $4 \times 1$ rib, $4 \times 4$ rib, half cardigan and full cardigan knit structure fabric
}

\begin{abstract}
This study investigates the result of various knit structure on various properties of rib fabric. The acrylic yarns were accustomed to make $4 \times 1$ rib, $4 \times 4$ rib, half cardigan and full cardigan structured fabrics using manual V-bed knitting machine during this analysis work. The consequences of knit structure were measured regarding drape coefficient percentage, bending length, flexural rigidity and tightness factor. The results disclosed that the fabric properties are greatly influenced by knit structures. $4 \times 4$ rib knit structured fabric showed the highest value for all tested properties except drape co-efficient and half cardigan knit structured fabric showed the lowest value. $4 \times 1 \mathrm{rib}$ knit fabric possessed the highest drape co-efficient percentage. The bending length and flexural rigidity was investigated in both wale and course direction. Simultaneously, surface and back sides bending length were also calculated. From the above mentioned data it's been known that the effect of knit structure on flexural rigidity in both wale and course direction were influenced in a very same chronological way. The highest tightness factor was observed for $4 \times 4$ rib structured fabric.
\end{abstract}

Keywords: Knitted fabric; Drape co-efficient; Bending length; Flexural rigidity; Tightness factor

Abbreviations: BL, bending length; CPI, course per inch; DC, drape co-efficient; FC, full cardigan; FR, flexural rigidity; HC, half cardigan; SL, stitch length; TF, tightness factor; WPI, wales per inch
Volume 5 Issue 2 - 2019

\author{
Md. Nura Alam Shiddique,' Md. Reazuddin \\ Repon, ${ }^{1,2}$ Rajib Al Mamun,' Mohaiminul \\ Quayum ${ }^{3,4}$ \\ 'Department of Textile Engineering, Khwaja Yunus Ali University, \\ Bangladesh \\ ${ }^{2}$ Department of Production Engineering, Faculty of Mechanical \\ Engineering and Design, Kaunas University of Technology, \\ Lithuania \\ ${ }^{3}$ Department of Textile Engineering, Mawlana Bhashani Science \\ and Technology University, Bangladesh \\ ${ }^{4}$ Production Division, Temakaw Fashion Limited, Bangladesh
}

Correspondence: Md. Reazuddin Repon, Department of Production Engineering, Faculty of Mechanical Engineering and Design, Kaunas University of Technology, Studentu str. 56, Kaunas LT-5 I 424, Lithuania Tel +370-66227098, Email reazmbstu.te@gmail.com

Received: August 28, 2018 | Published: April 10, 2019

\section{Introduction}

Knit fabrics are yarn-based fabrics that find significant appeal in the apparel market because knit fabrics offer exceptional comfort qualities and have long been preferred as fabrics in many kinds of clothing. ${ }^{1}$ The properties of knit fabrics are significantly influenced by many parameters including knit structure. The knit structure is basically produced by employing a continuous yarn or set of yarns to form a series of interlocking loops. The two basic types of knits are the weft and the warp knit. The use of warp and weft is largely analogous to the same terms used in woven structures with weft being along the fabric width and warp being along the fabric length. ${ }^{2}$ The applications area of knit fabrics are enlarging than before time and currently knits are using in numerous apparels such as sweaters, hosiery, T-shirts, golf shirts, sweat and exercise suits, lingerie, infant and children wear, swimming suits, gloves and figure shaping undergarments and so on. ${ }^{3}$ The popularity of knit fabrics in apparel products stems from many attractive features including the freedom of body movement in form-fitting garments, ease of care, resilience, soft draping quality and warmth in still air environments. ${ }^{4}$ Knits are also used in interior furnishing and in smaller quantities in upholstery and carpets. ${ }^{3}$ In function-focus fibrous products, knits have exhibited wide acceptance particularly in medical applications including splints, bandages, ointment pads, flat and tubular dressings, dialysis filters, incontinence pads and underwear, hospital cellular blankets and stretch terry sheets, band-aid fabrics, hospital privacy curtains, nets for handling burn victims, fabric for artificial heart valves, and nets for blood filtration, abdominal surgery and reconstructions..$^{4-9}$

The effects of various knit structures on the dimensional and/or physical properties of knitted fabrics have been analyzed by many researchers. ${ }^{10-17}$ Drape is noteworthy property of fabric which is utilized to observe the graceful appearance in use. A fabric is said to possess good drape ability when its configuration is pleasant to eye. ${ }^{18}$ The drape co-efficient of knitted fabric have been examined by many researchers. ${ }^{19-25}$ The flexibility of fabric can be measured by determining by bending length. High bending length indicates the stiffer of fabric. The bending length of knit fabric has been studied by some researchers. ${ }^{27-29}$ Fabric flexural rigidity has an effect on handling and comfort properties of apparel. A lower value of flexural rigidity supports the positive impression of sensorial comfort. The flexural rigidity of fabric has been observed by many researchers. ${ }^{27,30-32}$ Fabric tightness is also another considerable parameter to evaluate the fabric properties. Tightness factor indicates the looseness or tightness of knitted fabrics. Tightness factor of fabric has examined by several researchers. ${ }^{33-36}$ Tightness factor significantly influences the properties of knitted fabrics.

The goals of this study were to disclose the effect of $4 \times 1 \mathrm{rib}, 4 \times 4$ rib, half cardigan and full cardigan knit Structure on various properties such as drape co-efficient percentage, bending length, flexural rigidity and tightness factor of knitted fabric. 


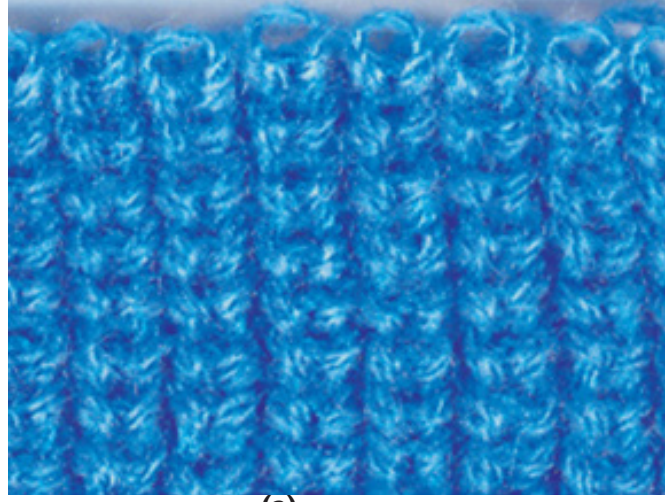

(a)

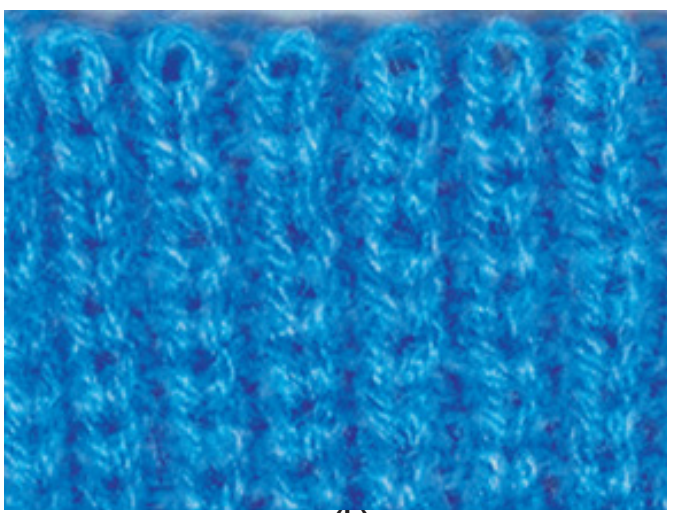

(b)

Figure I Photographs of machine-knitted half cardigan fabrics: (a) front view, (b) back view. ${ }^{37}$

(c)

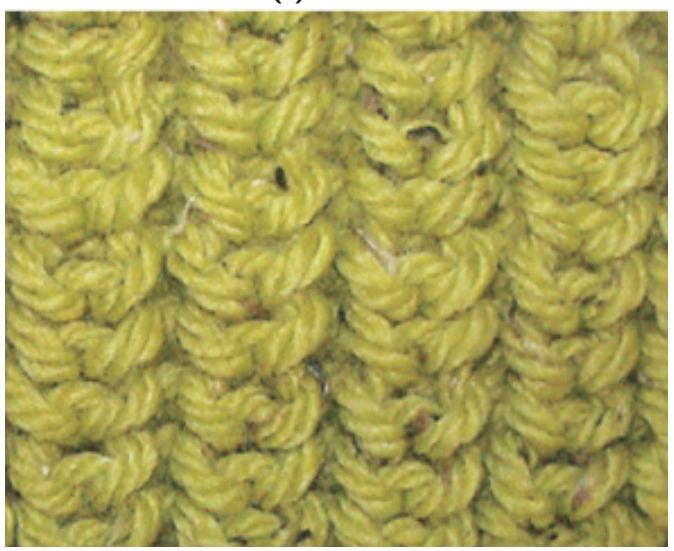

(d)

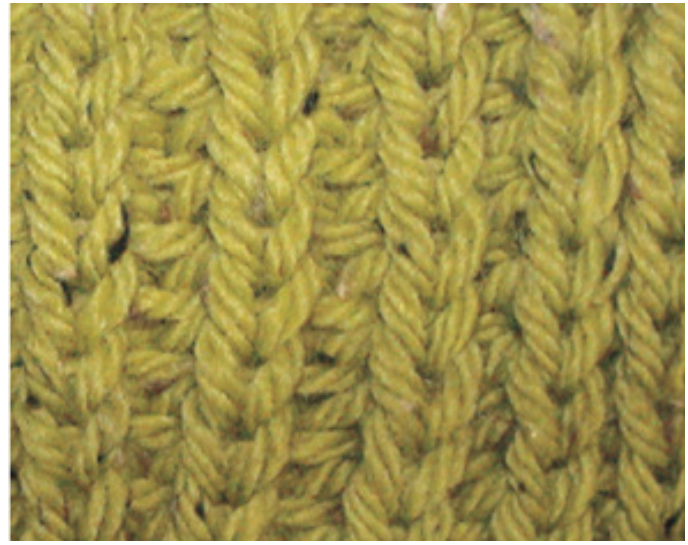

Figure 2 Photographs of hand-knitted half cardigan fabrics: (c) front view, (d) back view. ${ }^{37}$

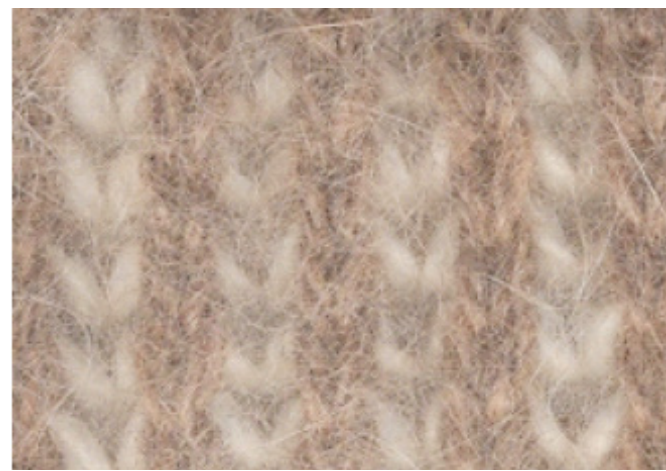

Figure 3 Photographs of the machine-knitted full cardigan fabric (front and back views are the same) ${ }^{38}$

\section{Experimental}

\section{Materials}

The acrylic yarns were collected from local market of Dhaka, Bangladesh. Different rib structured fabrics like $4 \times 1$ rib, $4 \times 4$ rib, half cardigan and full cardigan structured fabric were knitted with manual

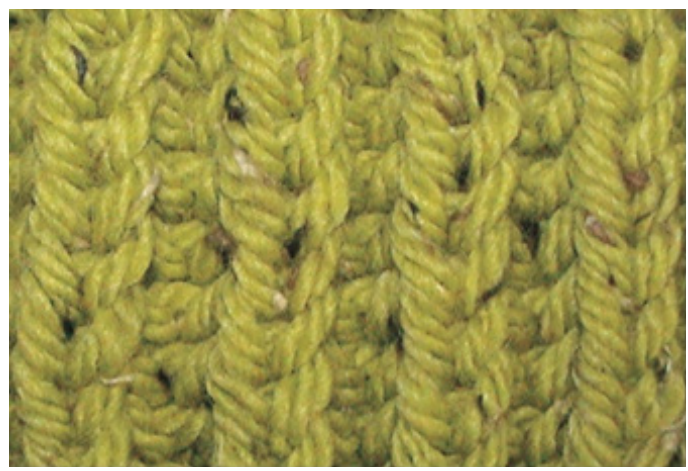

Figure 4 Photographs of the hand-knitted full cardigan fabric (front and back views are the same). ${ }^{38}$

V-bed knitting machine using full needle bed length, 3.5 machine gauge and single ended latch needle at fabric manufacturing and technology lab of Ahsanullah University of Science and Technology, Dhaka, Bangladesh. The wales per inch (WPI), course per inch (CPI) and stitch length of the specimens are mentioned in the Figures 5-7 respectively. 


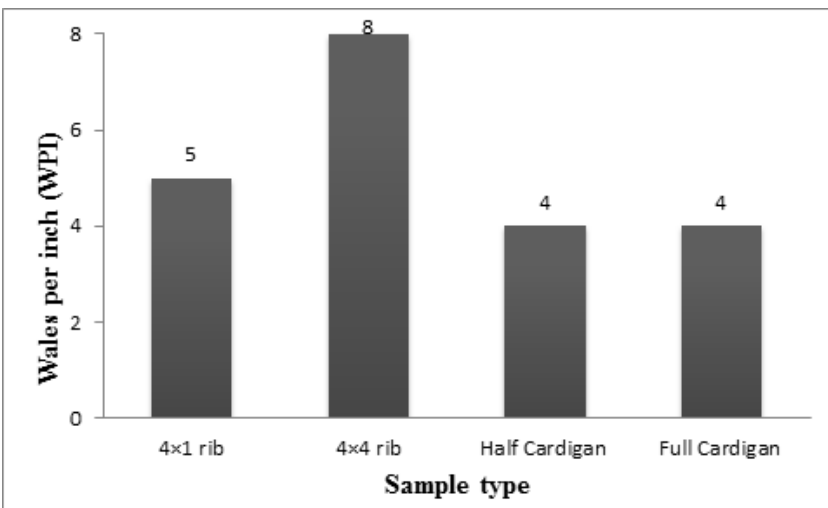

Figure 5 WPI of $4 \times 1$ rib, $4 \times 4$ rib, half cardigan and full cardigan fabric.

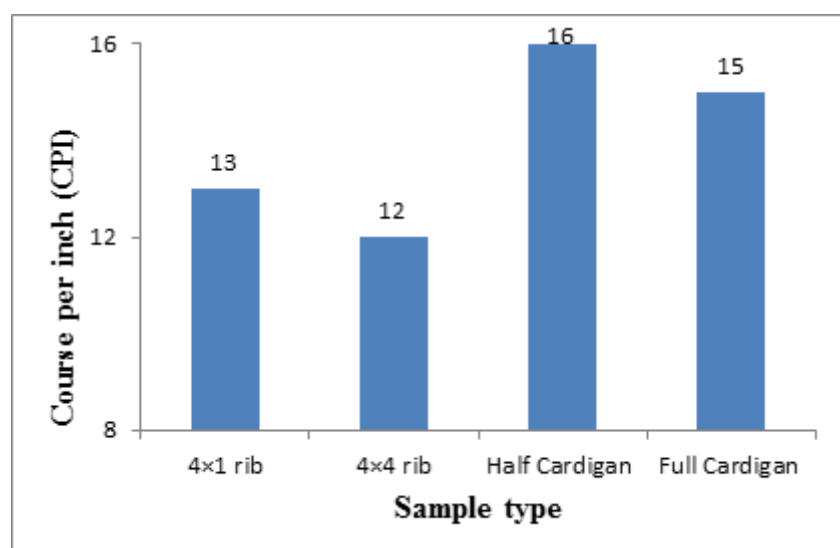

Figure $6 \mathrm{CPI}$ of $4 \times \mathrm{I}$ rib, $4 \times 4$ rib, half cardigan and full cardigan fabric.

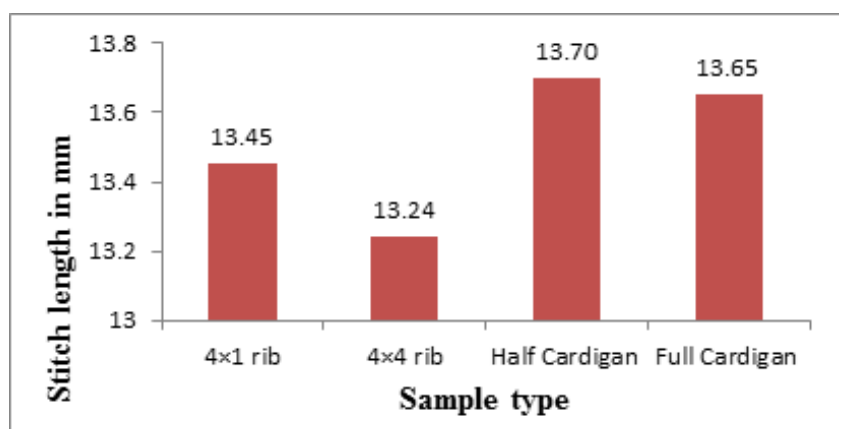

Figure 7 Stitch lengths of $4 \times 1$ rib, $4 \times 4$ rib, half cardigan and full cardigan fabric

\section{Methods}

Sampling: The specimens are identified as accordingly as stated Table 1.

Sample testing: The specimens were held in standard conditions $\left(\mathrm{RH}=65 \% \pm 2 \%, \mathrm{~T}=20^{\circ} \mathrm{C} \pm 2^{\circ} \mathrm{C}\right.$ ) according to the requirements of ISO 139:2005 before the investigation carried out. ${ }^{39}$

Measurement of WPI, CPI \& stitch length: The wales per inch (WPI) and course per inch (CPI) were measured by counting glass. ${ }^{40,41}$
Stitch length was determined by HATRA Course Length Tester (SDL International Ltd., England).

Table I Fabric structures, identification code and knitting notation

\begin{tabular}{|c|c|c|}
\hline $\begin{array}{l}\text { Fabric } \\
\text { structure }\end{array}$ & $\begin{array}{l}\text { Identification } \\
\text { code }\end{array}$ & Knitting notation \\
\hline $4 \times 1$ rib & R4I & \\
\hline $4 \times 4$ rib & R44 & \\
\hline $\begin{array}{l}\text { Half } \\
\text { Cardigan }\end{array}$ & $\mathrm{HC}$ & \\
\hline $\begin{array}{l}\text { Full } \\
\text { Cardigan }\end{array}$ & $\mathrm{FC}$ & \\
\hline
\end{tabular}

\section{Measurement of drape co-efficient}

The appropriate diameter of the template and corresponding size of paper ring was $30 \mathrm{~cm}$. Firstly, the test sample was calendared and conditioned in standard atmosphere. The selected template $(30 \mathrm{~cm})$ was placed on the specimen and marked round it. Then a pin was pushed through the template center in order to make a small hole in the middle of specimen. After cutting the specimen it was placed on the disc $(18 \mathrm{~cm})$ of Cusick drape tester and the lid was covered. A paper ring was placed on the lid around the locating disc. After that the light of the drape tester was switched on. A shadow of the specimen was found on the paper. Then the shadow was drawn on the paper. Drape co-efficient of fabrics were calculated using the following formula (i). ${ }^{23,42}$

$D C=\frac{\mathrm{W}_{\mathrm{S}}-\mathrm{W}_{\mathrm{d}}}{\mathrm{W}_{\mathrm{D}}-\mathrm{W}_{\mathrm{d}}} \times 100 \%$ (i)

Where,

$\mathrm{DC}=$ Drape Co-efficient.

$\mathrm{W}_{\mathrm{D}}=$ Weight of the paper whose area is equal to the area of the specimen.

$\mathrm{W}_{\mathrm{d}}=$ Weight of the paper whose area is equal to the area of the supporting disc.

$\mathrm{W}_{\mathrm{s}}=$ Weight of the paper whose area is equal to the projected area of the specimen.

\section{Determination of bending length}

Fabric bending length for each direction (course and wale directions) was measured five times using the cantilever method. 
Fabric bending length (c), a measure of the interaction between the fabric bending rigidity and weight, is defined as following formula (ii). ${ }^{26,28}$

$c=l f_{1}(\theta)$

Where, $f_{1}(\theta)=\left(\frac{\cos \frac{1}{2} \theta}{8 \tan \theta}\right)^{\frac{1}{3}}$ (ii)

$1=$ Cantilever length

$\theta=$ Deflection angle

\section{Determination of flexural rigidity}

Flexural rigidity $(\mathrm{G})$ is identified as the force couple required to bend a non-rigid structure to a unit curvature. This is a measure of stiffness associated with handle. Any formula from (iii) and (iv) can be used to measure the fabric flexural rigidity. ${ }^{43}$

$G=3.39 w_{1} c^{3} m g . c m$ (iii) Or

$G=w_{2} c^{3} \times 10^{3} \mathrm{mg} . \mathrm{cm}$ (iv)

Where, $\mathrm{c}=$ Bending length

$\mathrm{w}_{1}=$ Cloth weight in ounces per square yard

$\mathrm{w}_{2}=$ Cloth weight in gram per square centimeter

\section{Determination of tightness factor}

The tightness factor is the measurement of level of fabric density. ${ }^{34,35}$ The tightness factor was calculated by using formula (v). $\mathrm{T} . \mathrm{F}=\frac{\sqrt{\mathrm{T}}}{\mathrm{L}}(\mathrm{v})$

Where, T.F $=$ Tightness Factor

$\mathrm{T}=$ The linear density of yarn in Tex

$\mathrm{L}=$ Stitch length or loop length in $\mathrm{cm}$

\section{Results and discussion}

\section{Effect of fabric structures on drape co-efficient}

Drape determines the adjustment of clothing to the human silhouette and it's characterized by drape co-efficient (DC). The Figure 8 illustrates the effect of different fabric structures such as $4 \times 1 \mathrm{rib}, 4 \times 4$ rib, half cardigan and full cardigan on drape co-efficient percentage of knitted fabric. It is clearly evident from the figure 8 that the drape coefficient percentage truly influenced by fabric structures. The orders of the samples depending on drape of co-efficient percentage value were found as $\mathrm{R} 41>\mathrm{R} 44>\mathrm{FC}>\mathrm{HC}$. The drape co-efficient percentage among different structures, it is seen that $4 \times 1$ rib possesses the highest value and half cardigan possesses the lowest value. The figure 8 also showed that the drape co-efficient were $0.43 \%, 3.58 \%$, and $0.86 \%$ higher for the samples R44, HC and FC respectively compared to the sample R41.

\section{Effect of fabric structures on bending length}

The Figures 9 and 10 demonstrate the effect of fabric structures such as $4 \times 1 \mathrm{rib}, 4 \times 4 \mathrm{rib}$, half cardigan and full cardigan on bending length of knitted fabric. The Figure 9 is responsible for bending length in wale direction and the Figure 10 is responsible for bending length in course direction. The bending length in both sides (surface and back) of the fabric has calculated for both directions (wale and course) of the fabric. In wale direction, the highest bending length was recorded for the sample $4 \times 4$ rib and lowest value was observed for the sample of HC. In the other hand, in course direction, the highest bending length was recorded for the sample of $4 \times 4$ rib and lowest value was observed for the sample of HC. It is also clearly evident from the Figure 9, the bending length of back side showed lower than surface side except $4 \times 1 \mathrm{rib}$ and FC and from the Figure 10, the bending length of back side explained higher than surface side except $4 \times 4$ rib. The same value observed in both sides (surface and back) for the sample R44 and HC and same scenario identified for the sample R44 in course direction.

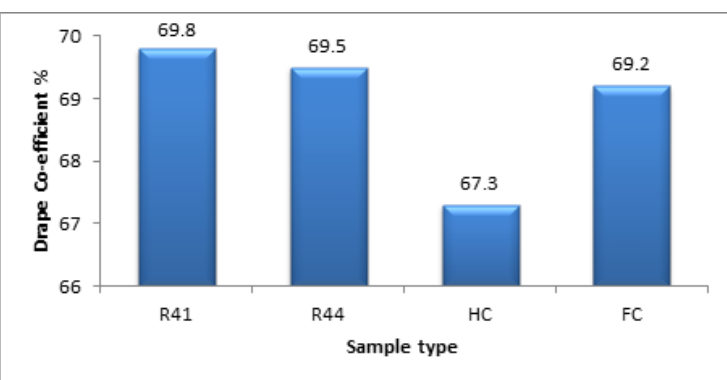

Figure 8 Effect of fabric structure on drape co-efficient.

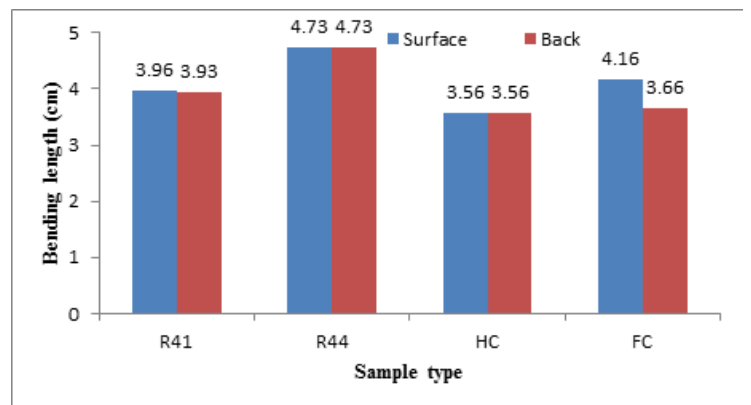

Figure 9 Effect of fabric structure on bending length in wale direction.

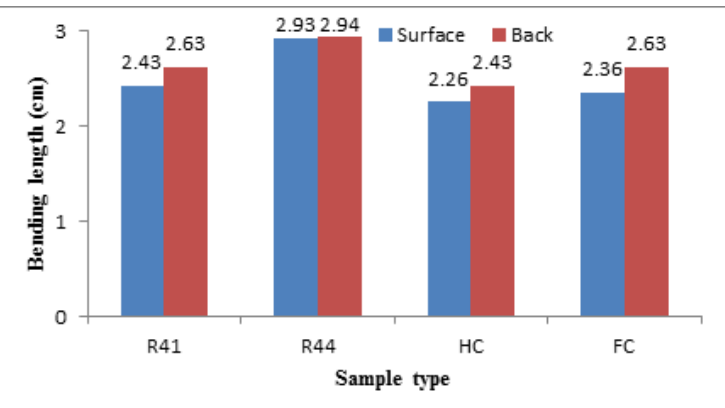

Figure 10 Effect of fabric structure on bending length in course direction.

\section{Effect of fabric structures on flexural rigidity}

The Figures 11 and 12 reveal the effect of fabric structures on flexural rigidity of $4 \times 1$ rib, $4 \times 4$ rib, half cardigan and full cardigan knitted fabric. The flexural rigidity in wale and course direction were measured and plotted in the Figures 11 and 12. It is clearly evident from the Figures 11 and 12 that the flexural rigidity in wale direction is higher than course direction. The flexural rigidity among different structures, it is seen that half cardigan possesses the lowest value and $4 \times 4$ rib possesses the highest value in both wale and course 
direction. Regarding flexural rigidity in wale direction, the orders of the samples were found as $\mathrm{R} 44>\mathrm{R} 41>\mathrm{FC}>\mathrm{HC}$. The flexural rigidity were $63.88 \%, 74075 \%$ and $66.98 \%$ lower for the samples R41, HC and $\mathrm{FC}$ respectively compared to the sample R44. Concerning flexural rigidity in course direction, the orders of the samples were found as $\mathrm{R} 44>\mathrm{R} 41>\mathrm{FC}>\mathrm{HC}$ as like as wale direction. The flexural rigidity were $59.76 \%, 69.83 \%$ and $64.12 \%$ lower for the samples R41, HC and FC respectively compared to the sample R44 in course direction.

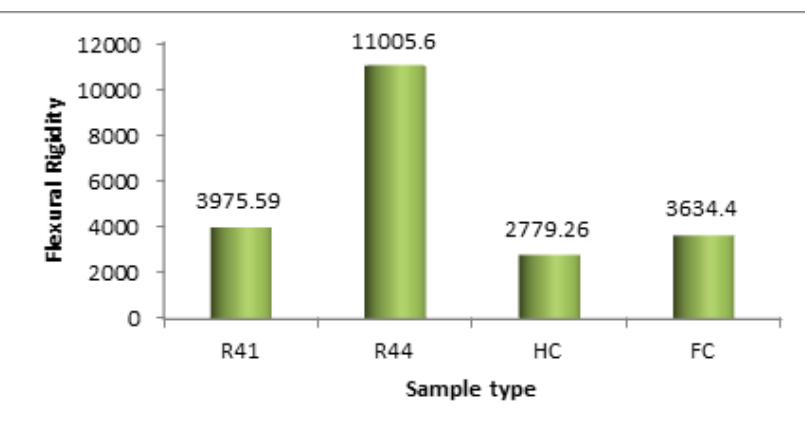

Figure I I Effect of fabric structure on flexural rigidity in wale direction.

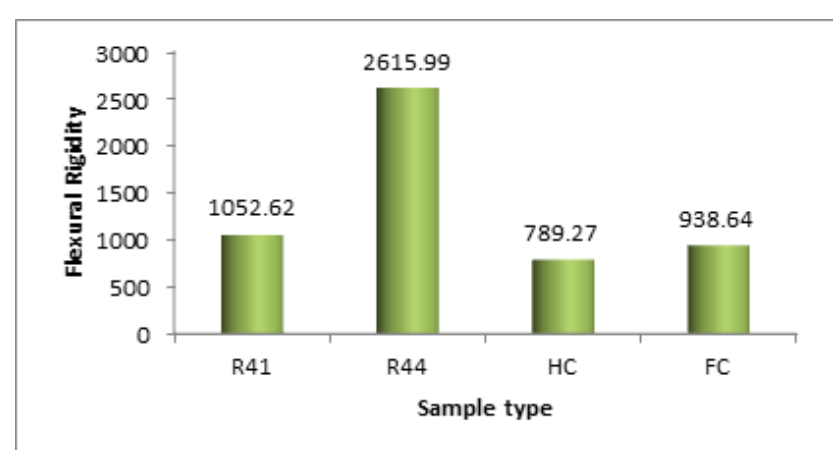

Figure 12 Effect of fabric structure on flexural rigidity in course direction.

\section{Effect of fabric structures on tightness factor}

Tightness factor has measured to evaluate the level of fabric density. The effects of different fabric structures such as $4 \times 1 \mathrm{rib}, 4 \times 4$ rib, half cardigan and full cardigan on tightness factor of rib knitted fabric are shown in the Figure 13. The orders of the samples were found as $\mathrm{R} 44>\mathrm{R} 41>\mathrm{FC}>\mathrm{HC}$ depending on the value of tightness factor. The highest value was identified for $4 \times 4$ rib and lowest value for half cardigan. The tightness factor were $2.48 \%, 4.96 \%$ and $4.13 \%$ lower for the samples R41, HC and FC respectively compared to the sample R44.

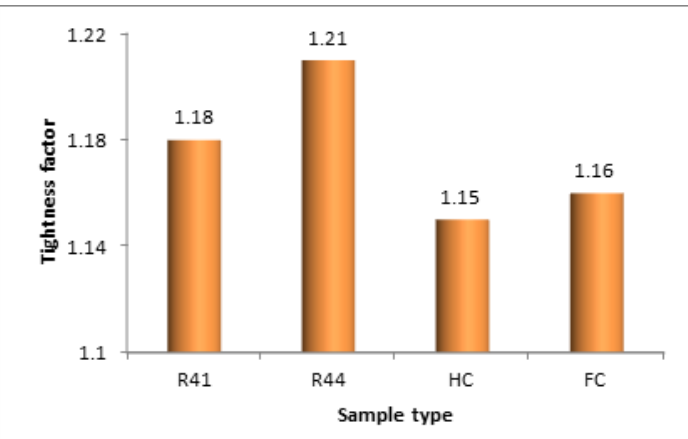

Figure 13 Effect of fabric structure on tightness factor.

\section{Conclusion}

It has been established that properties of the knitted fabrics are related to the knitting structure. The effect of $4 \times 1 \mathrm{rib}, 4 \times 4$ half cardigan and full cardigan knit structure on different properties of knitted fabric viz. drape co-efficient, bending length, flexural rigidity and tightness factor of rib knitted fabric has carried out in this work. The results disclosed that the fabric properties greatly influenced by knit structures. $4 \times 4$ rib knit structured fabric showed the highest value for all tested properties except drape co-efficient and half cardigan knit structured fabric showed the lowest value. $4 \times 1$ rib knit fabric possessed the highest drape co-efficient percentage. The bending length and flexural rigidity was investigated in both wale and course direction. At the same time, surface and back sides bending length were also calculated. From the above mentioned data it has been identified that the effect of knit structure on flexural rigidity in both wale and course direction were influenced in a same chronological way (half cardigan $<$ full cardigan $<4 \times 1<4 \times 4$ ). The highest tightness factor was observed as 1.21 for $4 \times 4$ rib structured knitted fabric.

Author contributions: The objectives and methodology of this works were proposed by Md. Reazuddin Repon and Md. Nura Alam Shiddique. The specimen fabrication, characterization and data treatment also carried out by Md. Reazuddin Repon and Md. Nura Alam Shiddique. The article was written by Md. Reazuddin Repon and revised by all authors.

\section{Funding}

This research received no specific grant from any funding agency in the public, commercial, or not-for-profit sectors.

\section{Acknowledgments}

The authors would like to thank the authority of Textile Engineering Department of Ahsanullah University of Science and Technology, Dhaka, Bangladesh for providing the tools and characterization supports for carrying out the experiments.

\section{Conflicts of interest}

The authors declare no conflict of interest.

\section{References}

1. Chen PL, Barker RL, Smith GW, et al. Handle of weft knit fabrics. Textile research journal. 1992;62(4):200-211.

2. Spencer DJ. Knitting Technology: a comprehensive handbook and practical guide. 3rd Ed. Woodhead Publishing; 2001. ISBN: 9781855737556.

3. El Mogahzy YE. 10 - Types of fabric for textile product design - engineering textiles. Woodhead Publishing; 2009:271-299.

4. Hatch KL. Textile Science. Minneapolis, NY: West Publishing Company; 1999. ISBN 10: 0314904719.

5. Anand SC. Technical fabric structures-2. Knitted fabrics. Handbook of Technical Textiles. Woodhead Publishing; 2016.

6. Zhang X, Ma P. Application of knitting structure textiles in medical areas. Autex Research Journal. 2018;18(2):181-191.

7. Czajka R. Development of medical textile market. Fibres \& Textiles in Eastern Europe. 2005;13(1):13-15.

8. Gokarneshan N, Dhatchayani U. Mini Review: Advances in Medical Knits. J Textile Eng Fashion Technol. 2017;3(2):621-625. 
9. Gokarneshan N, Dhatchayani U. Exploring the potentiality of knits for newer areas of medical applications. Sci J Biomed Eng Biomed Sci. 2017;1(1):007-019.

10. Candan C, Önal L. Dimensional, pilling, and abrasion properties of weft knits made from open-end and ring spun yarns. Textile Research Journal. 2002;72(2):164-169.

11. Nergis BU, Candan C. Performance of bouclé yarns in various knitted fabric structures. Textile research journal. 2006;76(1):49-56.

12. Ramgulam RB, Amirbayat J, Porat I. The objective assessment of fabric pilling. Part I: Methodology. Journal of the textile institute. 1993;84(2):221-226.

13. Candan C. Factors affecting the pilling performance of knitted wool fabrics. Turkish Journal of Engineering and Environmental Sciences. 2000;24(1):37-46.

14. Çeken F. An investigation about air permeability of wool/polyester and wool/acrylic knitted fabrics. Tekstil ve Konfeksiyon. 1997;2:111-115.

15. Choi MS, Ashdown SP. Effect of changes in knit structure and density on the mechanical and hand properties of weft-knitted fabrics for outerwear. Textile Research Journal. 2000;70(12):1033-1045.

16. Onal L, Candan C. Contribution of fabric characteristics and laundering to shrinkage of weft knitted fabrics. Textile Research Journal. 2003;73(3):187-191.

17. Kavușturan Y. The effects of some knit structures on the fabric properties in acrylic weft knitted outerwear fabrics. Tekstil Maraton. 2002:40-46.

18. Gaucher ML. The physical properties that influence the drape of knitted fabrics. MSc. thesis, Manitoba: University of Manitoba; 1979.

19. Kenkare N, May-Plumlee T. Evaluation of drape characteristics in fabrics. International Journal of Clothing Science and Technology. 2005;17(2):109-123.

20. Haque E, Alam MS. Effect of stitch lengths and yarn counts on areal density and drape behaviour of different weft knitted single jersey structures. American Journal of Applied Scientific Research. 2016;2(6):33-37.

21. Ragab A, Fouda A, El-Deeb H, et al. A simple method for measuring fabric drape using digital image processing. Journal of Textile Science and Engineering. 2017;7(5):1-8.

22. Eryuruk SH, Kalaoglu F. Analysis of the performance properties of knitted fabrics containing elastane. International Journal of Clothing Science and Technology. 2016;28(4):463-479.

23. Gaucher ML, King MW, Johnston B. Predicting the drape coefficient of knitted fabrics. Textile Research Journal. 1983;53(5):297-303.

24. Yücel Ö. Effect of seamed viscose fabrics on drape coefficient. Tekstil. 2012;61:101-106.

25. Kenkare N, May-Plumlee T. Fabric drape measurement: A modified method using digital image processing. Journal of Textile and Apparel, Technology and Management. 2005;4(3):1-8.

26. Oinuma R. Effect of stitch length on some properties of cotton $1 \times 1$ rib knitted fabrics. Journal of the Textile Machinery Society of Japan. 1990;36(3):91-95.
27. Goetzendorf-Grabowska B, Karaszewska A, Vlasenko VI, et al. Bending stiffness of knitted fabrics-comparison of test methods. Fibres \& Textiles in Eastern Europe. 2014;22(103):43-50.

28. Ghosh TK, Zhou N. Characterization of fabric bending behavior: a review of measurement principles. Indian Journal of Fibre \& Textile Research. 2003;28:471-476.

29. Mihailovic T, Asanovic K, Mihajlidi T. Complex estimation of woven fabrics bending ability. Indian Journal of Fibre \& Textile Research. 2007;32:453-458.

30. Kim K, Inui S, Takatera M. Prediction of bending rigidity for laminated weft knitted fabric with adhesive interlining. Textile Research Journal. 2013;83(9):937-946.

31. Jakubczyk J. Evaluating the bending rigidity of flat textiles with the use of an Instron tensile tester. Fibres \& Textiles in Eastern Europe. 2005;13(2):31-34.

32. Tohidi SD, Jeddi AA, Nosrati H. Analyzing of the woven fabric geometry on the bending rigidity properties. International Journal of Textile Science. 2013;2(4):73-80.

33. Azim AY, Islam MA, Morshed M, et al. Effect of fabric structure on rib fabric properties. European Scientific Journal. 2014;10(36):211-220.

34. Sitotaw DB, Subramanian KS. Study effect of twist multipliers on loop length, loop shape, and tightness factors of single jersey and rib knitted fabrics. Advances in Materials Science and Engineering. 2016:1-7.

35. Elzaher Eltahan EA, Sultan M, Mito AB. Determination of loop length, tightness factor and porosity of single jersey knitted fabric. Alexandria Engineering Journal. 2016;55(2):851-856.

36. Shiddique MN, Repon MR, Al Mamun R, et al. Evaluation of impact of yarn count and stitch length on pilling, abrasion, shrinkage and tightness factor of $1 \times 1$ rib cotton knitted fabrics. Journal of Textile Science and Engineering. 2018;8(5):1-6.

37. Kurbak A, Alpyildiz T. Geometrical models for cardigan structures part II: half cardigan. Textile Research Journal. 2009;79(18):1635-1648.

38. Kurbak A, Alpyildiz T. Geometrical models for cardigan structures part I: full cardigan. Textile Research Journal. 2009;79(14):1281-1300.

39. ISO 139:2005. Textiles - standard atmospheres for conditioning and testing. 2005.

40. IS 1963:1982. Methods for determination of threads per unit length in knitted fabrics. New Delhi: Bureau of Indian Standards.

41. Repon MR, Shiddique MN, Paul D, et al. Effect of yarn count \& stitch length on the fabric width, GSM, WPI and CP I of $1 \times 1$ rib fabrics. Int $J$ Text Sci. 2018;7(4):94-100.

42. Abdin Y, Taha I, El-Sabbagh A, et al. Description of draping behaviour of woven fabrics over single curvatures by image processing and simulation techniques. Composites Part B: Engineering. 2013;45(1):792-799.

43. Rantasalo SP. Propagation of flexural properties from fibre to fabric. Master of Science Thesis, Finland: Tampere University of Technology; 2015. 